\title{
Determinants of the use of Web 2.0 technologies for knowledge sharing in SMEs
}

\author{
Pedro Soto-Acosta ${ }^{1} \cdot$ Daniel Perez-Gonzalez $\cdot$ Simona Popa
}

Abstract Web 2.0 technologies are increasingly being used within all knowledge management processes. This paper extends previous studies on the use of Internet technologies and knowledge management by analyzing factors affecting knowledge sharing through Web 2.0 technologies within SMEs. Drawing upon the technologyorganization-environment framework, a model is developed to examine how distinct contextual factors influence the use of Web 2.0 technologies for knowledge sharing. A data set of Spanish SMEs is used to test the conceptual model and hypotheses. Results show that knowledge sharing through Web 2.0 technologies emerges from internal organizational and technological resources rather than from external pressure.

Keywords Knowledge sharing · SMEs · Internet · Web $2.0 \cdot$ technology adoption

\section{Introduction}

The term Web 2.0 was coined to distinguish between traditional static Web sites and interactive knowledge creation platforms, where users are expected to draw from and contribute to knowledge databases simultaneously (Xin et al. 2014). Several studies (e.g., Richards 2009) have analyzed the impact of the social web on knowledge management, while others (e.g., Levy 2009; Paroutis and Al Saleh 2009; Sigala and Chalkiti 2013) have coined the term Knowledge 2.0 to summarize the new trend in knowledge management. Knowledge Management 2.0 can be defined as the acquisition, creation and sharing of collective intelligence through social networks and communities of knowledge

P. Soto-Acosta (corresponding author)

Department of Management and Finance, University of Murcia, Campus de Espinardo, 30100 Espinardo (Murcia), Spain

Email: psoto@um.es

D. Perez-Gonzalez

Department of Business administration, University of Cantabria, Avda. de los Castros S/N, 39005 Santander (Cantabria), Spain

Email: daniel.perez@unican.es

S. Popa

Department of Management and Finance, University of Murcia, Campus de Espinardo, 30100 Espinardo (Murcia), Spain

Email: sp.popa@um.es 
(Sigala and Chalkiti 2013). Web 2.0 technologies build an Internet-based digital platform on which users can exchange information, express thoughts, and reconfigure existing knowledge, which, in turn, may lead to new and improved knowledge (Colomo-Palacios et al. 2013).

With the advent of the second generation Internet technologies, and the associated reduction of communication costs, firms are migrating toward Web 2.0 technologies for information and knowledge management (Colomo-Palacios et al. 2013). Internet technology characteristics of rapid search, access, retrieval and exchange of information make it suitable for collaboration and knowledge sharing between organizational members (Lopez-Nicolas and Soto-Acosta 2010). In addition to this, the Web 2.0 constitutes an Internet-based digital platform that enables the creation of social networks, facilitating information dissemination and knowledge sharing (Joo and Normatov 2013; Pan 2012). Consequently, firms are deploying Web 2.0 technologies such as social networking, wikis, and internal blogging to improve collaboration and knowledge sharing within their boundaries (Lim et al. 2010).

Effective adoption and use of Internet technologies are a major management concern (Soto-Acosta and Meroño-Cerdan 2008; Colomo-Palacios et al. 2013). Recent studies (e.g., Gu et al. 2012) are starting to analyze the adoption and use of Internet technologies within organizations and how these technologies support specific business processes. However, much of the existing research focuses on a single aggregate view of the organizational adoption and use of Internet technologies (e.g., Bordonaba-Juste et al. 2012; Hong and Zhu 2006; Soto-Acosta and Meroño-Cerdan 2008; Zhu and Kraemer 2005). These studies analyze the adoption and use of Internet technologies along the whole value chain (or a significant part of it). Thus, while existing research has expanded our knowledge, little is known about the determinants that motivate the adoption and use of specific Internet technologies such as the Web 2.0 for knowledge management processes, including knowledge acquisition/creation, knowledge dissemination, and knowledge utilization.

Furthermore, existing research has shown that, although businesses have extensively adopted Internet technologies, actual usage is an important link to business value, and this link is sometimes missing, especially in small and medium-sized enterprises (SMEs) (D'Arcy and Devaraj 2012; Devaraj and Kohli 2003; Zhu and Kraemer 2005). In this sense, studies in SMEs (e.g., Lopez-Nicolas and Soto-Acosta 2010) suggest that, although having a proper information technology (IT) infrastructure can facilitate knowledge creation, it does not necessarily mean that knowledge is created. Thus, to transfer or create knowledge, interaction of some kind has to take place between the actors. In this sense, knowledge sharing has been considered essential to the creation, dissemination and utilization of knowledge (Valkokari et al. 2012). Moreover, although the literature suggests that findings from studies examining knowledge management practices in large companies are unlikely to be generalizable to SMEs, very few and recent studies focus on this specific type of firms (Chan et al. 2012; Huy et al. 2012; Lopez-Nicolas and Soto-Acosta 2010). Meanwhile, SMEs are of enormous importance for economic growth, employment and wealth creation.

To respond to the above gaps in the literature, this paper develops a conceptual model, grounded in the Technology-Organization-Environment (TOE), to analyze the key factors that facilitate the use of Web 2.0 technologies for knowledge sharing. With 
this aim in mind, the rest of our study is organized as follows. First, the literature review and hypotheses are presented. Second, the research methods drawing from a sample consisting of SMEs are described. Third, data analysis and results are examined and, finally, conclusions, limitations and future research guidelines are presented.

\section{Theoretical background and hypotheses}

The review of the literature suggests that Tornatzky and Fleischer's (1990) technologyorganization-environment (TOE) framework is appropriate to study the factors that influence Web 2.0 technologies use for knowledge sharing. The TOE framework conceptualizes the context of adoption and implementation of technological innovations as consisting of three aspects: technological context, organizational context and environmental context. The technological context refers to the characteristics of the technological innovation, the organizational context describes characteristics of the organizations, and the environmental context implies characteristics of the environment in which the adopting organizations operate (Tornatzky and Fleischer 1990; Thong 1999).

The TOE framework has emerged as the main theoretical framework to analyze the different factors which affect the adoption and use of Internet technologies. Very recent studies make use of this theoretical framework to analyze factors affecting Internet technologies adoption and use (e.g., Bordonaba-Juste et al. 2012; Chan et al. 2012; Gu et al. 2012; San Martín et al. 2012). Although specific measures within the three contexts vary across different studies, the TOE framework has been examined in various IT domains including electronic business (e.g., Bordonaba-Juste et al. 2012), electronic collaboration (eg. Chan et al. 2012) and m-commerce (e.g., San Martín et al. 2012). Thus, drawing upon literature analyzing Internet technologies adoption and use, this paper, based on the TOE framework, analyzes factors that affect Web 2.0 technologies use for knowledge sharing.

\subsection{Technological context}

Given the technology-driven nature of knowledge management processes, the extent of Web 2.0 technologies use for knowledge sharing depends on firms' technology competence. At the same time, technology competence relies on tangible and intangible resources, though the latter are more likely to generate competitive advantages (O'Sullivan and Dooley 2010; Soto-Acosta and Meroño-Cerdan 2008). Studies using the TOE framework have found tangible IT resources such as IT integration as enablers of Internet technologies adoption and use (e.g., Zhu et al. 2006; Zhu and Kraemer 2005). IT integration facilitates communications and collaboration which, in turn, may enhance knowledge sharing. IT intangibles such as IT expertise have been identified as factors influencing the level of use of Internet technologies (e.g., Bordonaba-Juste et al. 2012). Firms that have IT professionals are more likely to adopt IT innovations because they can better adapt IT applications to their organizations (Lin and Lee 2005). Therefore, IT integration and IT expertise may be important technological issues in explaining the use of Web 2.0 technologies for knowledge sharing. The following hypotheses incorporate our expectations: 
Hypothesis 1: There is a positive relationship between IT integration and the extent of the use of Web 2.0 technologies for knowledge sharing.

Hypothesis 2: There is a positive relationship between IT expertise and the extent of the use of Web 2.0 technologies for knowledge sharing.

\subsection{Organizational context}

Firms need to develop interaction networks that allow individuals not only to access the same information but also to come together and collaborate through the network (Alavi and Leidner 2001). This is even more crucial when exchanging tacit knowledge, which requires more interaction between employees (Fox 2000). Knowledge sharing happens when units and members interact. However, besides technology enablers, employees need to be willing to collaborate and share knowledge. Extant research has recognized that organizational factors may constrain or facilitate the implementation and use of Internet technologies (Colomo-Palacios et al. 2012; Gu et al. 2012; Soto-Acosta et al. 2013). For instance, organizational human resource (HR) practices that create a commitment-based environment may affect the organizational social climate that motivates employees to work together and share knowledge (Collins and Smith 2006). As a consequence, a strong climate for cooperation between knowledge workers is expected to positively affect knowledge sharing among them. The literature distinguishes between transaction-based HR practices, which focus on individual short-term exchange relations, and commitment-based HR practices, which emphasize mutual long-term exchange relations, suggesting that the latter may contribute to such a social climate (Tsui et al. 1997). In fact, Collins and Smith (2006) found that, by creating a certain social climate, commitment-based HR practices positively influence knowledge sharing among workers. Based on this discussion, the following hypothesis is proposed:

Hypothesis 3: There is a positive relationship between commitment-based HR practices and the extent of the use of Web 2.0 technologies for knowledge sharing.

\subsection{Environmental context}

Competition depends on the business environment in which a firm operates. Porter's (1985) five competitive forces framework refers to horizontal competition (threat of substitutes, existing competitors and potential new entrants) and vertical competition (the bargaining power of suppliers and customers). Existing research (e.g., Chong et al. 2009; Wang et al. 2010; Zhu et al. 2006) has found that competition intensity is an important driver of Internet technologies adoption (Chong et al. 2009; Wang et al. 2010; Zhu et al. 2006). Yet other studies (e.g., Del Aguila-Obra and Padilla-Melendez 2008; Wang and Ahmed 2009) have encountered that external pressure from customers and suppliers influence e-business adoption (Del Aguila-Obra and Padilla-Melendez 2008; Wang and Ahmed 2009). Therefore, competition intensity is expected to drive organizations to adopt Web 2.0 technologies. However, research (e.g., Chan et al. 2012; Zhu et al. 2006) has also shown that competition may deter firms from using Internet technologies, so challenging the traditional wisdom about competition and innovation diffusion. Zhu et al. (2006) found a positive relation between competition and e-business adoption, but a negative relation between competition and the extent of e-business use. Similarly, Chan et al. (2012) found that competition intensity is negatively related to the extent of e- 
collaboration use in SMEs. Thus, use of Internet technologies is less tied to competition intensity than initially thought in both large and small business. This discussion leads to the following hypotheses:

Hypothesis 4: There is a negative relationship between bargaining power of customers and the extent of the use of Web 2.0 technologies for knowledge sharing.

Hypothesis 5: There is a negative relationship between the bargaining power of suppliers and the extent of the use of Web 2.0 technologies for knowledge sharing.

The set of relations is illustrated in Figure 1.

Figure 1. Research model

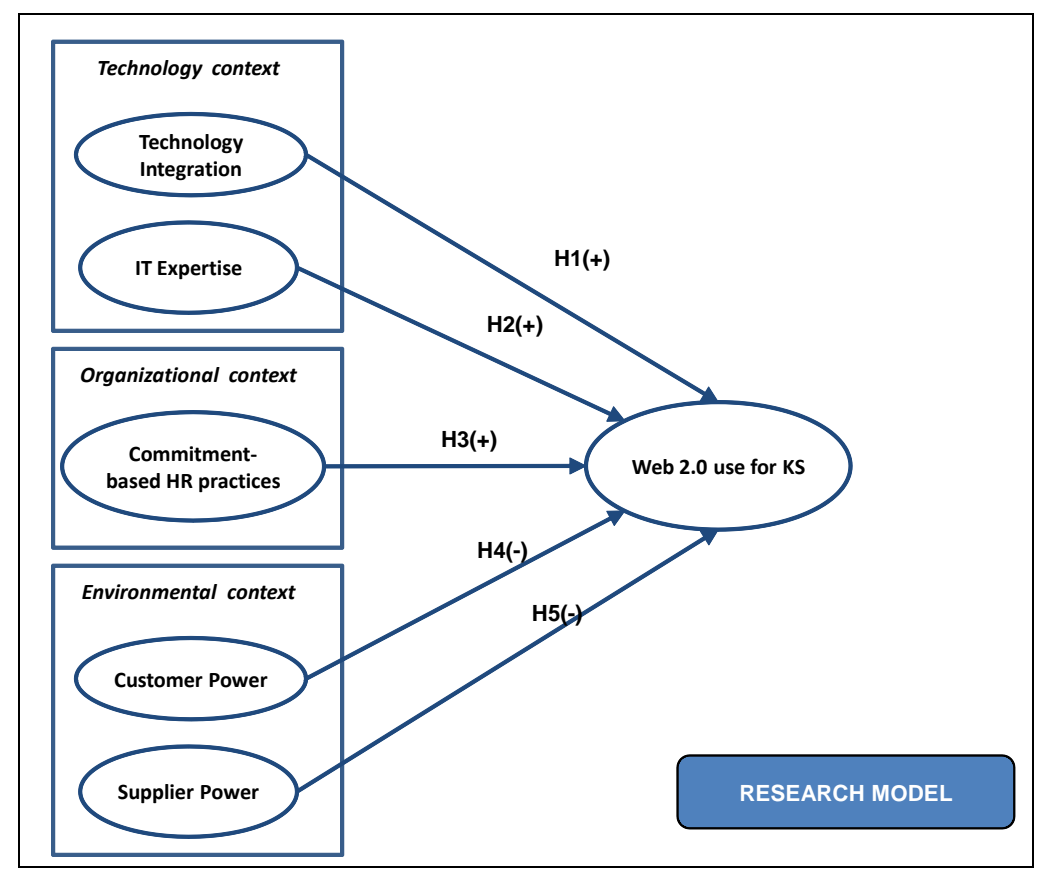

\section{Research methodology}

\subsection{Data collection and sample}

The organisations selected for this study are SMEs from Spain. Previous research in the Spanish context (e.g., Meroño-Cerdan et al. 2008a; 2008b) suggested that using IT is crucial for firms with at least 10 and over. To ensure a minimum firm complexity in which ITs may be relevant, the population considered in this study was the set of all Spanish SMEs, with 14 employees or more, located in the Region of Murcia, which have their primary business activity in one of the following business activities: manufacturing, commercial, services and construction. A total of 2246 were identified and contacted for participation. Data collection was conducted following two phases. First, a pilot study was performed and, following that, a questionnaire was conducted. Five SMEs were randomly selected from a database to perform the pilot study. Based on these responses and subsequent interviews with participants in the pilot study, minor modifications were made to the questionnaire for the next phase of data collection. Responses from these five pilot-study firms were not included in the final sample. The survey was administered to 
the CEO of the companies via personal interview and the unit of analysis for this study was the company. In total, 535 valid questionnaires were obtained, yielding a response rate of 23.8 percent. The profile of respondents is presented in table 1.

Table 1 Sample characteristics

\begin{tabular}{ll}
\hline Profile of respondents & Percentage \\
\hline Industry & \\
Manufacturing & $32.07 \%$ \\
Commercial & $29.17 \%$ \\
Services & $15.22 \%$ \\
Construction & $23.55 \%$ \\
Number of employees & \\
$10-49$ & $74.02 \%$ \\
$50-249$ & $25.98 \%$ \\
\hline
\end{tabular}

The dataset was examined for potential bias in terms of non-response by comparing the characteristics of early and late participants in the sample. These comparisons did not reveal significant differences in terms of general characteristic and model variables, suggesting that non-response did not cause any survey bias.

\subsection{Measures}

Measurement items were introduced on the basis of a careful literature review. The survey questionnaire was originally designed in English as the key measures used in this study were operationalized using already established instruments published in that language. We used the back-translation method to ensure the validity of the translation (Brislin, 1980). Existing scales were translated into Spanish and, where necessary, slight wording changes were made to adapt the questions to the context of the study. The research instrument was pretested with 5 different researchers and managers. Our primary objective was to detect inadequate wording and facilitate the ease of administering the instrument. The results from the pretest showed no particular bias, but some respondents had trouble understanding certain items. We revised the wording of these items to improve their readability. Several constructs were directly operationalized by observed variables. IT expertise was measured by the number of IT professionals (Bordonaba-Juste et al. 2012; Zhu et al. 2006; Zhu et al. 2004). Customer and Supplier Power were measured following two of Porter's (1985) concepts of five competitive forces. Such operationalization has been previously used in the IT literature (Thong 1999; Zhu et al. 2004). Other variables were operationalized as multi-item constructs. Technology Integration was measured as the extent of back-end and front-end information systems and databases connectivity (Zhu et al. 2006). Commitment-based HR practices were operationalized from previous research (Collins and Smith 2006; Delery and Doty 1996; Youndt et al. 1996) work. Overall, 8 items were adapted to measure Commitment-based HR practices. The use of Web 2.0 technologies for knowledge sharing measured the extent employees participate in organizational forums, use Web 2.0 technologies for 
building collective knowledge and upload information on organizational social networks or wikis (Sigala and Chalkiti 2013).

\subsection{Instrument validation}

The measures from the dataset were refined by assessing their unidimensionality and reliability. First, an initial exploration of unidimensionality was made using principal component factor analyses. In each analysis, eigenvalues were greater than 1 , lending preliminary support to a claim of unidimensionality in the constructs. Next, confirmatory factor analysis (CFA) was performed to establish the required convergent validity, discriminant validity, and reliability of the constructs. This study uses EQS 6.1 to estimate the measurement model. The measurement model presented a good fit to the data $\left(\chi^{2}(29)=36.529, \mathrm{p}=0.158 ; \mathrm{CFI}=0.98 ; \mathrm{IFI}=0.98 ; \mathrm{GFI}=0.97 ; \mathrm{RMSEA}=0.04\right)$. All traditionally reported fit indexes were within the acceptable range. This study calculated reliability of measures using Bagozzi and Yi's (1998) composite reliability index and Fornell and Larcker's (1981) average variance extracted index. Based on the CFA assessment, the measurement models were further refined and then fitted again. Insignificant items were dropped.

For all the measures, both indices were higher than the evaluation criteria, namely 0.6 for composite reliability and 0.5 for the average variance extracted. With regard to convergent, after dropping insignificant items, all estimated standard loadings are significant $(\mathrm{p}<0.01)$ and of acceptable magnitude (see table 2 ), suggesting good convergent validity.

Table 2 Measurement model: confirmatory analysis and scale reliability

\begin{tabular}{|c|c|c|c|c|}
\hline Construct & Indicators & S. Loadings & t-value & Reliability \\
\hline \multirow{2}{*}{ Technology integration } & TI1 & 0.767 & -- & \multirow{2}{*}{$\begin{array}{r}\mathrm{CR}=0.78 \\
\mathrm{AVE}=0.6\end{array}$} \\
\hline & $\mathrm{TI} 2$ & 0.834 & 4.20 & \\
\hline IT professionals & ITP & na & na & na \\
\hline \multirow{2}{*}{$\begin{array}{l}\text { Training support and } \\
\text { employees' interest }\end{array}$} & HR1 & 0.742 & -- & \multirow{2}{*}{$\begin{array}{r}\mathrm{CR}=0.75 \\
\mathrm{AVE}=0.61\end{array}$} \\
\hline & HR2 & 0.814 & 6.59 & \\
\hline \multirow{3}{*}{$\begin{array}{l}\text { Carreer plans and } \\
\text { evaluation reporting }\end{array}$} & HR5 & 0.43 & -- & \multirow{3}{*}{$\begin{array}{r}\mathrm{CR}=0.80 \\
\mathrm{AVE}=0.57\end{array}$} \\
\hline & HR7 & 0.78 & 6.52 & \\
\hline & HR8 & 0.94 & 6.33 & \\
\hline Customer power & $\mathrm{CP}$ & na & na & na \\
\hline Supplier power & $\mathrm{CP}$ & na & na & na \\
\hline \multirow{3}{*}{$\begin{array}{c}\text { Web } 2.0 \text { use for } \\
\text { Knowledge Sharing }\end{array}$} & WKS1 & 0.677 & -- & \multirow{3}{*}{$\begin{array}{c}\mathrm{CR}=0.78 \\
\mathrm{AVE}=0.56\end{array}$} \\
\hline & WKS2 & 0.606 & 4.23 & \\
\hline & WKS 3 & 0.597 & 4.24 & \\
\hline
\end{tabular}


To assess the discriminant validity, Fornell and Larcker's (1981) criterion, that the square root of average variance extracted for each construct (diagonal elements of the correlation matrix in table 3) should be greater than the absolute value of inter-construct correlations (off-diagonal elements), was used. All constructs met this criterion, suggesting that the items share more variance with their respective constructs than with other constructs. Table 3 also provides an overview of the means, standard deviations and correlations of the constructs.

Table 3 Descriptive statistics and discriminant validity

\begin{tabular}{|c|c|c|c|c|c|c|c|c|c|}
\hline \multirow{2}{*}{ Constructs } & \multirow{2}{*}{ Mean } & \multirow{2}{*}{$\begin{array}{l}\text { Standard } \\
\text { deviation }\end{array}$} & \multicolumn{7}{|c|}{ Correlation matrix } \\
\hline & & & $(1)$ & $(2)$ & (3) & $(4)$ & (5) & $(6)$ & $(7)$ \\
\hline 1. Technology integration & 2.67 & 1.22 & 0.80 & & & & & & \\
\hline 2. IT expertise & 0.73 & 2.79 & $0.11 *$ & na & & & & & \\
\hline $\begin{array}{l}\text { 3. Training support and } \\
\text { employees' interest }\end{array}$ & 3.88 & 0.90 & $0.09 *$ & 0.02 & 0.78 & & & & \\
\hline $\begin{array}{l}\text { 4. Career plans and } \\
\text { evaluation reporting }\end{array}$ & 3.18 & 0.91 & $0.33^{* *}$ & 0.04 & $0.33 * *$ & 0.76 & & & \\
\hline 5. Customer power & 3.61 & 1.09 & $-0.06 * *$ & -0.04 & 0.04 & -0.01 & na & & \\
\hline 6. Supplier power & 3.03 & 1.08 & 0.08 & -0.01 & -0.02 & 0.06 & $0.22 * *$ & na & \\
\hline $\begin{array}{l}\text { 7. Web } 2.0 \text { use for } \\
\text { Knowledge Sharing }\end{array}$ & 2.35 & 1.28 & $0.03 *$ & $0.23^{*}$ & $0.35^{* *}$ & $0.16^{* *}$ & $0.23 *$ & 0.06 & 0.77 \\
\hline
\end{tabular}

Significance levels: $p<0.05^{*} ; p<0.01^{* *}$; na. Variance extracted is not applicable to the single-item constructs.

Diagonal values in bold represent the square root of the AVE

This study measures commitment-based HR practices as a single construct made up of two dimensions: Training support and employees interest and career plans and evaluation reporting. A second-order factor analysis demonstrated that the two dimensions reflect a higher-order construct $\left(\chi^{2}(3)=6.701\right.$; CFI $=0.99$; $\mathrm{IFI}=0.99$; GFI = 0.99; RMSEA = 0.04)

\section{Results}

This paper estimated the structural model with the EQS 6.1 software package, using maximum likelihood estimation techniques to test the model. The fit of the model is satisfactory $\left(\chi^{2}(51)=56.282, p=0.283\right.$; RMSEA=0.043; CFI=0.99 IFI=0.99 GFI=0.99), suggesting that the nomological network of relations fits the data and the validity of the measurement scales.

Figure 2 shows the standardized path coefficients with their respective significant levels. Hypothesis 1 is was not supported, indicating that technology integration is not related to the use of Web 2.0 technologies for knowledge sharing in SMEs. Hypothesis 2 was supported $(0.16, \mathrm{p}<0.05)$, this result shows that hiring specialized IT personnel in the firm is an important factor for knowledge sharing through Web 2.0 technologies. Hypothesis 3 was supported $(0.79, \mathrm{p}<0.01)$, being commitment-based HR practices the strongest factor in the proposed model. This indicates that the presence of commitment- 
based HR practices is a critical factor driving knowledge sharing through Web 2.0 technologies. Hypothesis 4 was supported $(-0.29, \mathrm{p}<0.01)$, while hypothesis 5 is not supported, indicating a negative relationship between customer power and the use of Web 2.0 technologies for knowledge sharing and a non-significant relationship between supplier power and knowledge sharing through Web 2.0 technologies. Implications of these results are discussed in the next section.

Figure 2. Empirical results

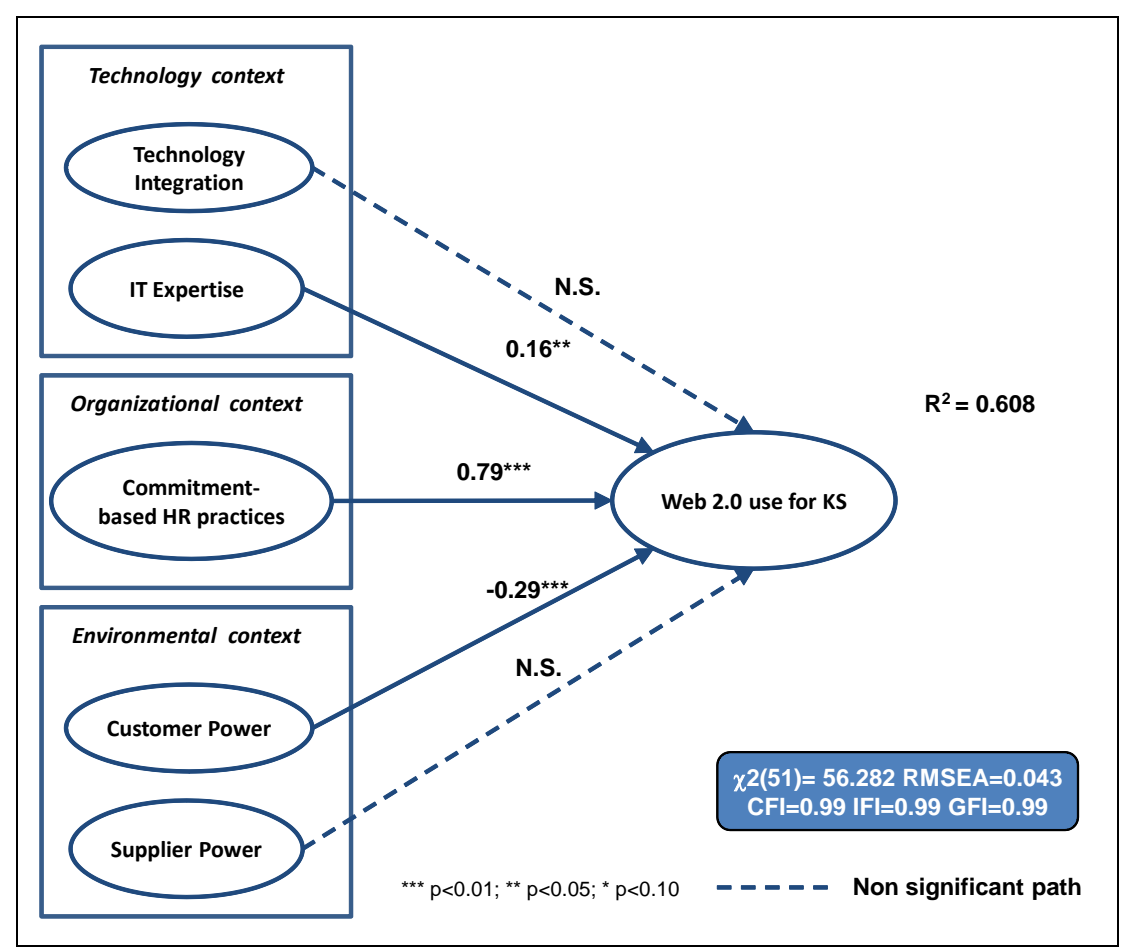

\section{Discussion}

This paper investigates the effects of five TOE factors on the use of Web 2.0 technologies for knowledge sharing by using a data set of SMEs. The empirical results have revealed that factors have differential effects.

Regarding the technological context, results suggested that though IT expertise is positively associated with the use of Web 2.0 technologies for knowledge sharing, a nonsignificant relationship was found for the relationship between technology integration and the use of Web 2.0 technologies for knowledge sharing. The first finding supports recent research (Bordonaba-Juste et al. 2012), which found that IT expertise is one of the main factors that affect the extent of Internet/e-business use. However, the second finding counters existing research (e.g., Zhu et al. 2006; Zhu and Kraemer 2005), which found that technology integration is positively related to the extent of Internet/e-business use (Zhu et al. 2006) and positively associated to Internet/e-business value (Zhu and kraemer 2005). A possible explanation to this can be that previous studies have focused on aggregate measures of the organizational adoption and use of Internet technologies and, 
within that context, technology integration may be more crucial. In contrast, within the specific context of knowledge sharing through Web 2.0 technologies in SMEs, intangible IT resources (O'Sullivan and Dooley 2010) such as hiring specialized IT personnel seem to be the major technological drivers.

With Regard to the organizational context, the effect of commitment-based HR practices on the use of Web 2.0 technologies for knowledge sharing is analyzed. The results show a positive relation between these two constructs. This finding confirms previous research (Collins and Smith 2006), which, though not focusing on Internet technologies, encountered that commitment-based HR practices were significantly related to knowledge sharing among workers. Results regarding factors from the environmental context suggest a negative relationship between customer power and the use of Web 2.0 technologies for knowledge sharing and a non-significant relationship between supplier power and the use of Web 2.0 technologies for knowledge sharing. These findings partially support recent research (e.g., Chan et al. 2012; Zhu et al. 2006), which found that competition may detract firms from using Internet technologies. Our finding also confirms previous research using SMEs. Chan et al. (2012) found that competition intensity is negatively related to the extent of e-collaboration use in SMEs. Thus, knowledge sharing through Web 2.0 technologies emerges from internal organizational and technological resources rather than from external pressure.

\section{Conclusions, limitations and future research}

Organizations' survival and success depend on the effort and interactions of employees as they possess the skills and generate knowledge to transform new ideas into innovations. Since firms are increasingly adopting Web 2.0 technologies for collaboration and knowledge sharing (Joo and Normatov 2013; Singala and Chaltiki 2013), it becomes essential to assimilate Internet technologies to support information sharing and knowledge sharing within firms. This study examines the influence of five contextual factors on knowledge sharing through Web 2.0 technologies. This paper makes several contributions to the literature. First, it focuses on SMEs. Previous studies in the literature tend to focus in large businesses, with very few and recent studies analyzing Internet technologies adoption and use in SMEs (e.g., Chan et al. 2012; Chong et al. 2009; Huy et al. 2012). Based on a large sample of SMEs, this paper favors the generalizability of results to SMEs. Second, using the TOE framework the usage of Web 2.0 technologies for collaboration and Knowledge sharing is conceptualized within SMEs. More specifically, we extend previous work by analyzing how the use of specific Internet technologies such as the Web 2.0 affects knowledge sharing. Third, we theorized and tested differential effects of the TOE factors on the use of Web 2.0 technologies for knowledge sharing.

While the contributions of the present study are significant, it has some aspects which can be addressed in future research. The sample consisted of SMEs from the Region of Murcia (Spain). Similar studies in different countries are likely to show different results, especially when considering high Internet intensity countries such as the US and Finland. Therefore, in future research a sampling frame which combines firms from different countries could be used in order to provide a more international perspective to the subject. This research takes a static, cross-sectional picture of contextual factors affecting the use of Web 2.0 technologies for knowledge sharing, 
which makes it difficult to address the issue of how contextual factors and their importance may change over years. A longitudinal study could enrich the findings. Moreover, the key informant method was used for data collection. This method, while it has advantages, also suffers from the limitation that the data reflects the opinions of one person. Future studies could consider research designs that allow data collection from multiple respondents within an organization. These suggestions should be taken into account in future studies to increase the validity of our findings.

\section{Refencences}

Alavi M, Leidner, DE (2001) Review: knowledge management and knowledge management systems: conceptual foundations and research issues. MIS Quarterly 25(1):107-36

Bagozzi RP, Yi Y (1998) On evaluation of structural equations models. Journal of the Academy of Marketing Science 16(1):74-94

Bordonaba-Juste V, Lucia-Palacios L, Polo-Redondo Y (2012) Antecedents and consequences of ebusiness use for European retailers. Internet Research 22(5): 532-550

Brislin RW (1980) Translation and content analysis of oral and written material. In H.C. Triandis, J.W. Berry (Eds.), Handbook of cross-cultural psychology, 2, 349-444. Allyn \& Bacon: Boston.

Chan FTS, Chong AY-L, Zhou L (2012) An empirical investigation of factors affecting e-collaboration diffusion in SMEs. International Journal of Production Economics 138(2): 329-344

Chong AYL, Ooi KB, Lin B, Tang SY (2009) Influence of interorganizational relationships on SMEs' ebusiness adoption. Internet Research 19(3): 313-331

Collins CJ, Smith KG (2006) Knowledge exchange and combination: the role of human resource practices in the performance of high-technology firms. Academy of Management Journal 49(3):544-560

Colomo-Palacios R, Casado-Lumbreras C, Soto-Acosta P, Misra S, García-Peñalvo FJ (2012) Analyzing human resource management practices within the GSD context. Journal of Global Information Technology Management 15(3):30-54

Colomo-Palacios R; Casado-Lumbreras C; Soto-Acosta P \& Misra S (2013) Providing knowledge recommendations: an approach for informal electronic mentoring. Interactive Learning Environments 22(2): 221-240

D'Arcy J, Devaraj S (2012) Employee misuse of information technology resources: Testing a contemporary deterrence model. Decision Sciences 43(6):1091-1124

Del Aguila-Obra A, Padilla-Melendez A (2008) Organizational factors affecting internet technology adoption. Internet Research 16(1):94-110

Delery JE, Doty DH (1996) Modes of theorizing in strategic human resource management: test of universalistic contingency, and configurational performance predictions. Academy of Management Journal 39(4):802-835

Devaraj S and Kholi R (2003) Performance impacts of information technology: is actual usage the missing link?. Management Science 49(3):273-289

Fornell C, Larcker F D (1981) Evaluating structural equation models with unobservable variables and measurement error. Journal of Marketing Research 18(1):39-50

Fox S (2000) Communities of practice, foucault and actor network theory. Journal of Management Studies 37(6):853-67

Gu V C, Cao Q, Duan W (2012) Unified Modeling Language (UML) IT adoption - A holistic model of organizational capabilities perspective. Decision Support Systems 54(1): 257-269

Hong W, Zhu K (2006) Migrating to Internet-based e-commerce: factors affecting e-commerce adoption and migration at the firm level. Information \& Management 43(2):204-221 
Huy LV, Rowe F, Truex D, Huynh MQ (2012) An empirical study of determinants of e-commerce adoption in SMEs in Vietnam an economy in transition. Journal of Global Information Management 20(3):23-54

Joo J, Normatov I (2013) Determinants of collective intelligence quality: comparison between Wiki and Q\&A services in English and Korean users. Service Business 7(4): 687-711

Levy M (2009) Web 2.0 implications on knowledge management. Journal of Knowledge Management 13(1):120-134

Lim S, Trimi S, Lee H (2010) Web 2.0 service adoption and entrepreneurial orientation. Service Business 4(3-4):197-207

Lopez-Nicolas C, Soto-Acosta P (2010) Analyzing ICT adoption and use effects on knowledge creation: An empirical investigation in SMEs, International Journal of Information Management 30(6):521-528

Meroño-Cerdan A, Soto-Acosta P, Lopez-Nicolas, C (2008a) Analyzing collaborative technologies' effect on performance through intranet use orientations. Journal of Enterprise Information Management 21(1): 39-51

Meroño-Cerdan A, Soto-Acosta P, Lopez-Nicolas, C (2008b) Analyzing collaborative technologies' effect on performance through intranet use orientations. International Journal of e-Collaboration 4(4): 33-50

O'Sullivan D, Dooley L (2010) Collaborative Innovation for the Management of Information Technology Resources. International Journal of Human Capital and Information Technology Professionals 1(1):16-30

Pan Z (2012) Opinions and networks: how do they effect each other. Computational Economics 39(2):157171

Paroutis S, Al Saleh A (2009) Determinants of knowledge sharing using web 2.0 technologies. Journal of Knowledge Management 13(4):52-63

Porter ME (1985) Competitive Advantage. Free Press, New York

Richards D (2009) Social software/web 2.0 approach to collaborative knowledge engineering. Information Sciences 179(15):2515-2523

San Martín S, López-Catalán B, Ramón-Jerónimo MA (2012) Factors determining firms' perceived performance of mobile commerce. Industrial Management \& Data Systems 112(6):946-963

Sigala M, Chalkiti K (2013) Investigating the exploitation of web 2.0 for knowledge management in the Greek tourism industry: An utilisation-importance analysis, Computers in Human Behavior 30(1): 800-812

Soto-Acosta P, Meroño-Cerdan A (2008): Analyzing e-Business value creation from a resource-based perspective, International Journal of Information Management 28(1):49-60

Soto-Acosta P, Ramayah T, Popa S (2013) Explaining intention to use an enterprise resource planning system: A replication and extension. Tehnički vjesnik 20(3): 397-405

Thong JYL (1999) An integrated model of information systems adoption in small businesses. Journal of Management Information Systems 15(4):187-214

Tornatzky LG, Fleischer M (1990) The process of technological innovation. Lexington, MA: Lexington Books, Lexington

Tsui AS, Pearce JL, Porter, LW (1997) Alternative approaches to the employee-organization relationship: Does investment in employees pay off?. Academy of Management Journal 40:1089-1121

Valkokari K, Paasi J, Rantala T (2012) Managing Knowledge within networked innovation. Knowledge Management Research \& Practice 10(1):27-40

Wang Y, Ahmed P (2009) The moderating effect of the business strategic orientation on e-commerce adoption: evidence from UK family run SMEs. Journal of Strategic Information System 18(1):16-30

Wang YM, Wang YS, Yang YF (2010) Understanding the determinants of RFID adoption in the manufacturing industry. Technological Forecasting and Social Change 77:803-815

Xin JY, Ramayah T, Soto-Acosta P, Popa S, Ping TA (2014) Analyzing the use of the Web 2.0 for brand awareness and competitive advantage: An empirical study in the Malaysian hospitability industry. Information Systems Management. In press, DOI 10.1080/10580530.2014.890425

Youndt MA, Snell SA, Dean Jr JW, Lepak, DP (1996) Human resource management, manufacturing strategy and firm performance. Academy of Management Journal 39(4):836-866 
Zhu K, Kraemer K (2005) Post-adoption variations in usage and value of e-business by organizations: cross-country evidence from the retail industry. Information Systems Research 16(1):61-84

Zhu K, Kraemer KL, Xu S (2006) The process of innovation assimilation by firms in different countries: a technology diffusion perspective on e-business. Management Science 52(10):1557-1576

Zhu K, Kraemer KL, Xu S, Dedrick J (2004) Information technology payoff in e-business environments: an international perspective on value creation of e-business in the financial services industry. Journal of Management Information Systems 21(1):17-54

\section{Appendix Measures}




\section{Appendix. Measures}

\begin{tabular}{|c|c|}
\hline Variables & Description \\
\hline \multicolumn{2}{|l|}{ Technology Integration } \\
\hline TI1 & $\begin{array}{l}\text { Extent to which the website is electronically integrated with back-end } \\
\text { systems and databases (1-5) }\end{array}$ \\
\hline IR2 & $\begin{array}{l}\text { Extent to which company databases are electronically integrated to } \\
\text { that of business partners (clients, suppliers...) (1-5) }\end{array}$ \\
\hline IT expertise (ITP) & Number of IT professionals (\#) \\
\hline \multicolumn{2}{|l|}{$\begin{array}{l}\text { Commitment-based } H R \\
\text { practices }\end{array}$} \\
\hline HR1 & Employees’ interest are taken into account for decision-making (1-5) \\
\hline HR2 & Our company support employees willing to take further training (1-5) \\
\hline HR3 & Our company helps employees achieving work-life balance (1-5) \\
\hline HR4 & Selection processes are formalized and rigorous (1-5) \\
\hline HR5 & Our company has established career paths (1-5) \\
\hline HR6 & Promotion is based on objective criteria (seniority, objectives...) (1-5) \\
\hline HR7 & Performance appraisals are conducted on a regular basis (1-5) \\
\hline HR8 & Employees are informed about their performance appraisals (1-5) \\
\hline Customer Power & Extent of pressure clients exert on purchasing conditions (1-5) \\
\hline Supplier Power & Extent of pressure suppliers exert on purchasing conditions (1-5) \\
\hline \multicolumn{2}{|l|}{$\begin{array}{l}\text { Web } 2.0 \text { use for } \\
\text { Knowledge Sharing. }\end{array}$} \\
\hline W2KS1 & $\begin{array}{l}\text { Extent to which the employees participate in organizational electronic } \\
\text { discussion forums (1-5) }\end{array}$ \\
\hline W2KS2 & $\begin{array}{l}\text { Extent to which Web } 2.0 \text { technologies are used for building collective } \\
\text { knowledge (1-5) }\end{array}$ \\
\hline W2KS3 & $\begin{array}{l}\text { Extent to which the employees upload information on organizational } \\
\text { social networks or wikis (1-5) }\end{array}$ \\
\hline
\end{tabular}

Note. (1-5): five-point Likert-type scales; (\#): continuous variable. 